\title{
Rising to the Challenge of COVID-19: Pivoting to Online and Project-Based Physiotherapy Student Placements in Contemporary Professional
}

\section{Settings}

\author{
*Vidya Lawton ${ }^{a}$, Rebecca Vaughan ${ }^{a}$, Taryn .M. Jones ${ }^{a} \&$ Verity Pacey ${ }^{a}$ \\ a: Macquarie University, Australia
}

\begin{abstract}
Online and project-based student placements in sport and corporate settings were incorporated within the Macquarie University Doctor of Physiotherapy following the restriction of face-to-face delivery during the COVID-19 pandemic. This study explores student and educator perceptions of these placements, and analyses student performance results to provide future recommendations. The mixed-methods design included a student survey, semi-structured educator interviews and quantitative analysis of student assessment performance comparing 2020 to 2018/2019 cohorts. Quantitative survey data were described, with proportional differences between groups analysed. Open-ended survey responses and interview transcripts were thematically analysed, and integration of all results was performed. Themes derived from 24 student surveys highlighted that the learning experiences and skills required for online and project-based placements were varied and valuable. Analysis of 176 students' performance showed differences between performance and applicability of assessment items in 2020 placements in comparison to previous years, although all students met performance requirements. Analysis of eight educator interviews identified that online and project-based placements changed experiences for all stakeholders and highlighted the need for enhanced educator and student communication and organisation for the placement to be successful. Online and project-based placements were considered a better reflection of contemporary work practices, producing valuable deliverables to the business. Three final integrated themes were identified regarding online and project-based elements of placements: learning experiences of students differed, skills for students and educators differed, and placements were representative of real-world work. A hybrid approach that incorporates both online and onsite placement time and includes a projectbased component is recommended for future placements. Project-based and online elements
\end{abstract}

*Corresponding Author: Vidya Lawton, Department of Health Sciences, Faculty of Medicine, Health and Human Sciences, Macquarie University NSW 2109

Email: vidya.lawton@mq.edu.au

Journal URL: https://publications.coventry.ac.uk/index.php/pblh

Lawton, V., Vaughan, R., Jones, T. M., \& Pacey, V. (2021). Rising to the challenge of COVID-19: Pivoting to online and project-based physiotherapy student placements in contemporary professional settings. International Journal of Practice-based Learning in Health and Social Care, Care, 9(2), 21-38, DOI 10.18552/ijpblhsc.v9i2.747 unrestricted non-commercial use, distribution, and reproduction in any medium, provided the original work is properly cited and is unaltered. 
provide genuine and valuable learning opportunities for physiotherapy students in preparation for real-world work.

\section{Keywords: clinical placements; coronavirus pandemic; online placements; physiotherapy; project-based placements}

\section{Introduction}

Clinical experiences, often called clinical placements or practice placements, are an integral part of health profession education programs, providing students with the ability to develop the depth and breadth of knowledge, skills and attributes required for practice (DeClute et al., 1993). Placements should mirror the healthcare landscape, and the needs of the profession (Bacopanos \& Edgar, 2015). To reflect the scope of the profession and real-world practice of contemporary physiotherapists, the Macquarie University Doctor of Physiotherapy (DPT), a 3-year Masters (extended) entry-level physiotherapy degree in Sydney, Australia, has purposefully expanded clinical education beyond traditional placements in hospital and community settings. Students apply academic content covering risk factor identification, recovery management, and performance optimisation within Work, Health and Safety (WHS) placements in a corporate setting, and sport placements with physiotherapists of community sport clubs and teams.

COVID-19 disrupted face-to-face placements globally, requiring higher education institutions to quickly pivot to ensure students could still engage in learning experiences and develop the competencies and capabilities required for professional practice. In Australia, Government imposed lockdown orders resulted in corporate sites closing their offices, and community sports competitions ceased. Consequently, Macquarie University's DPT clinical education team, in collaboration with WHS and sport educators, developed online project-based placements to enable students to continue to engage actively and meaningfully during the COVID-19 pandemic.

Online education is not a new concept. Over the last two decades rural and remote health and education providers have utilised online learning in order to combat distance and access (Seymour-Walsh, 2020). Online resources have also been found to enhance the face-to-face teaching of practical physiotherapy skills (Preston et al., 2012). However, placements in the traditional face-to-face format play a significant part of students' educational experiences, with many students perceiving it necessary for the development of discipline specific clinical skills, such as face-to-face interaction and 'hands-on' training with instant feedback from educators (Milanese et al., 2013).

In addition to the need to develop the skills required for the modern online environment, contemporary practice requires professionals to work collaboratively on long-term projects that are designed to enhance the well-being and performance of company employees and athletes. Project-based learning involves engaging students in a collaborative problem-solving approach to investigate and/or pose solutions to complex real-world problems (Darling-Hammond, 2008). However, despite this style of learning closely mirroring contemporary work practices across all industries, project-based learning has not been optimised within the higher education sector (Guo et al., 2020; Lee et al., 2014). Furthermore, projectbased learning has not been incorporated deeply into physiotherapy student placements despite having been delivered successfully in other health profession education programs (Hunt, 2005; Prigg \& Mackenzie, 2002). COVID-19 presented an opportunity to provide authentic, future-focused projectbased learning tasks, and the delivery of placements in an online environment, mirroring the contemporary landscape for health professionals working within WHS and sport settings.

Therefore, to evaluate the shift to online and project-based placements in sport and WHS settings during the COVID-19 pandemic, this study aimed to explore student and educator perspectives of the placements. The assessment of performance in comparison to previous student cohorts who completed traditional face to face placements was also analysed in order to provide recommendations for future placements that best reflect the post-COVID environment.

\section{Methods}

A mixed methods study design was implemented following ethical approval from Macquarie University Human Research Ethics Committee (Ethics number 52021937224303). 


\section{Context}

The context for this study is two student physiotherapy placements, one within a corporate setting and one within a sport setting, each 70 hours in length. These placements are embedded within two academic units focusing on physiotherapy in workplace and recreation settings and health system complexity. Academic content is then directly applied within the placement settings.

Prior to 2020, sport placements were conducted in a fully on-site format, with students embedded within a sporting club or team. The placement focused predominantly on the development of discrete clinical skills in an 'on-field' environment at training sessions and/or game days. WHS placements took place in a fully on-site format within corporate settings. Project-based learning had begun to be embedded in WHS placements with students using their discipline specific skills to complete a project that had been selected by the site, as well as participating in other on-site activities.

In 2020, due to the impact of COVID-19, major changes were necessary. Within each sport placement, a project-based element was introduced, codesigned with site educators to ensure specificity and value to each site. Project-based placements were delivered online once community sport paused. WHS placements moved to a fully project-based focus, with all placements conducted online for the duration of the COVID-impacted shutdown of businesses. Some students were able to return to some on-site activities late in their sport or WHS placement as COVID-19 restrictions eased.

For the purpose of this article, placement formats were classified as face-to-face, where students would complete their placement on-site with ongoing face-to-face supervision from the educator, or online, where placement hours were completed remotely with regular supervision via online meetings.

Furthermore, placements can also be described as being project-based, with a focus on completing a large piece of work across the placement duration, or as being focused on discrete skills developed on-field within sport settings, or on-site in corporate settings. Hybrid placements were defined as a placement that contained a mix of face-to-face and online elements, with either a project and/or discrete skill activities.

\section{Student perspectives of online and project-based placements}

\section{Participants}

Students who completed sport and WHS placements in 2020 were invited to participate in an anonymous online survey.

\section{Data collection and analysis}

A purpose-built survey was created to investigate student perspectives of these new online and projectbased elements of placements. The survey comprised of Likert scale, multiple-choice and open-ended questions regarding the types of projects completed (and their outcomes or deliverables), student perceptions of their learning experiences, the skills developed during online and project-based components of the placements, and student recommendations for future placements.

\section{Student clinical performance}

\section{Participants}

Students who completed sport and WHS placements between 2018 and 2020 were included in this aspect of the study.

\section{Outcome measures}

Since 2013, student performance has been evaluated using the Assessment of Physiotherapy Practice (APP) (Dalton, M., 2009) in sport placements, and the Interprofessional Capability Assessment Tool (ICAT) (Brewer, 2012) in WHS placements. The APP is a standardised, reliable and valid assessment tool (Dalton et al., 2011; Dalton et al., 2012) used to assess the performance of physiotherapy students during traditional 5-week block placements. No studies have validated this tool within the sports setting or over an integrated 70 hours placement. The ICAT is a three-item instrument assessing client-centred service, client safety and quality, and collaborative practice. While the ICAT has not been validated to date, it is commonly used within interprofessional education and research (Brewer \& Stewart-Wynne, 2013; El-Awaisi et al., 2016). 


\section{Data collection and analysis}

Data collection included individual APP item scores, ICAT item grades, and the number of APP items scored for each student. If a student does not have the opportunity to demonstrate the performance indicator for an APP item, it is marked Not Applicable (N/A).

\section{Educator perspectives of online project-based placements}

\section{Participants}

Educators who had supervised students in both 2020 and 2019 sport or WHS placements were invited to participate in an interview. The research team identified and recruited all eligible sport and WHS site educators to capture diversity of experiences and perspectives. Data collected during the interview included educator setting and role, the number of student placements supervised in 2019 and 2020, placement format and type.

\section{Data collection and analysis}

Interviews were conducted via Zoom, an online audio and video conferencing platform, by a member of the Macquarie University clinical team (VL, RV, TV), in a semi structured format (see Appendix 1. for interview guide). As physiotherapists and members of the clinical team, the interviewers had previously been responsible for sourcing, and supporting educators and students during placements. Interviews were recorded with consent and transcribed initially by Zoom but verified for accuracy by two researchers in the team. Transcripts were emailed to participants to confirm accuracy and provide any further clarification.

\section{Data Analysis}

Descriptive analysis of participant demographics, quantitative survey responses and APP and ICAT items were conducted using SPSS v26 (IBM statistics). Categorical data was presented as frequency and percentage, and continuous data as mean (range). Mean differences in on-site hours completed by students undertaking hybrid placements was analysed using a difference between two means calculated using the PEDro Calculator (Physiotherapy Evidence Database Confidence Interval Calculator) and presented as mean difference $(95 \% \mathrm{CI})$. Proportional differences between survey response groups and APP N/A items were compared using an Absolute Risk Reduction measure using the PEDro Calculator (Herbert. 2013) and presented as percentage difference (95\% CI). Proportions of scores of individual APP and ICAT items within the 2018/2019 cohorts and the 2020 cohort were compared using Chi-Square analysis, with post-hoc analysis performed when a significant difference was identified between the proportion of scores on a particular APP item. Statistical significance was defined as $\mathrm{p}<0.05$ for all tests.

Open-ended survey responses and educator interview transcripts were reviewed line-by-line by two members (VL, RV) of the research team to identify concepts, themes and ideas using the grounded theory approach (Corbin \& Strauss, 2008). Three researchers (VL, RV and VP) then discussed, identified and agreed upon key themes and sub-themes, and finalised the integrated themes through discussion with the remaining team member $(\mathrm{TJ})$.

\section{Results}

\section{Student perspectives of online project-based placements}

Thirty-three of the 58 students eligible entered the survey. Four students did not provide consent and a further 5 students did not answer any questions so were not included. Final analysis was completed on the 24 remaining respondents, with one participant not completing all questions. This represents $41 \%$ of eligible students. None of the respondents completed a fully face-to-face placement for either sport or WHS placements. Fully online placements were completed by 17 (71\%) for Sport placements, and 21 (88\%) of respondents for WHS placements. Of the 24 respondents, 14 (58\%) did both their sports and WHS placements fully online. The remaining respondents completed a hybrid placement. No student completed a hybrid placement for both sport and WHS. Respondents who completed hybrid placements reported the average amount of face-to-face delivery of placements was 53 hours of the total 70 hours (range 35-65 hours) in sport placements, which is significantly greater than the average of 14 hours (6-20 hours) reported in WHS placements, a difference of means of 39 hours (95\% CI 36 to 42 hours). 
Sport placement projects were reported to include data analysis of injury reporting, development of evidence-based injury prevention programs, evaluation of injury prevention programs within sporting clubs, and development of a coaches' manual for swimming athletes. Projects within the WHS setting were reported to include data analysis of injury reporting, development of evidence-based injury prevention programs, development and implementation of mental health and wellbeing programs, delivery of online exercise classes for employees working at home, WHS policy documents and infographics for workers with home set-up ergonomic recommendations.

Over half $(53 \%)$ of the students who completed an online sports placement and $67 \%$ of those who completed an online WHS placement Agreed or Strongly Agreed that they had developed useful skills for their future studies or career (Table 1), a non-statistically significant difference of $18 \%$ (95\% CI -16 $41 \%)$. When asked about the contact and support from educators, there were more students who did a fully online and project-based WHS placement who Agreed or Strongly Agreed that they had enough contact and support compared to those did a fully online and project-based sports placement (86\% vs $65 \%$ respectively), however this difference was not statistically different $(21 \%, 95 \%$ CI -6 - 46\%) (Table 1$)$. When asked about their perception of what they believe the ideal make up of a placement to be, nine students (38\%) stated they believed a sports placement should ideally be fully on-site, compared with just 1 student (4\%) reporting this to be ideal for WHS placements, a statistically significant difference of $33 \%$ (95\% CI $10 \%-53 \%)$.

Table 1

Student survey responses based on type of placement students undertook, sports and WHS in either fully online or hybrid mode.

\begin{tabular}{|c|c|c|c|c|c|}
\hline \multirow[t]{2}{*}{ Survey Questions } & & \multicolumn{2}{|l|}{ Sports } & \multicolumn{2}{|l|}{ WHS } \\
\hline & & $\begin{array}{l}\text { Online } \\
n=17\end{array}$ & $\begin{array}{l}\text { Hybrid } \\
n=7\end{array}$ & $\begin{array}{l}\text { Online } \\
n=21\end{array}$ & $\begin{array}{l}\text { Hybrid } \\
n=3\end{array}$ \\
\hline \multirow{5}{*}{$\begin{array}{l}\text { I developed useful skills that } \\
\text { I will be able to use in my } \\
\text { future studies/career during } \\
\text { my placement. }\end{array}$} & Strongly Agree & $1(6 \%)$ & $2(29 \%)$ & $4(19 \%)$ & $0(0 \%)$ \\
\hline & Agree & $8(47 \%)$ & $4(57 \%)$ & $10(48 \%)$ & $2(67 \%)$ \\
\hline & Neither & $2(12 \%)$ & $0(0 \%)$ & $4(19 \%)$ & $1(33 \%)$ \\
\hline & Disagree & $5(29 \%)$ & $1(14 \%)$ & $2(10 \%)$ & $0(0 \%)$ \\
\hline & Strongly Disagree & $1(6 \%)$ & $0(0 \%)$ & $1(5 \%)$ & $0(0 \%)$ \\
\hline \multirow{5}{*}{$\begin{array}{l}\text { I felt as though I had enough } \\
\text { contact with, and support } \\
\text { from my educator during my } \\
\text { placement. }\end{array}$} & Strongly Agree & $3(18 \%)$ & $2(29 \%)$ & $6(29 \%)$ & $0(0 \%)$ \\
\hline & Agree & $8(47 \%)$ & $3(43 \%)$ & $12(57 \%)$ & $2(67 \%)$ \\
\hline & Neither & $3(18 \%)$ & $0(0 \%)$ & $2(10 \%)$ & $1(33 \%)$ \\
\hline & Disagree & $3(18 \%)$ & $2(29 \%)$ & $0(0 \%)$ & $0(0 \%)$ \\
\hline & Strongly Disagree & $0(0 \%)$ & $0(0 \%)$ & $1(5 \%)$ & $0(0 \%)$ \\
\hline
\end{tabular}

Two themes were derived from the open ended questions. Subthemes and illustrative quotations from open ended questions are provided in Table 2.

\section{Theme 1: The learning experience and skills required for online clinical placements was varied.}

All respondents described a unique learning experience with online placements, and project-based elements. Many students reported different aspects of some skills, such as communication and professional skills, became more important in the online environment, while some aspects of communication, such as non-verbal demonstration, became less critical. Students reported development of skills including organisation and teamwork, and commented that online placements and projects helped 
develop their self-directed learning skills. Some students gained telehealth consultation experience and reported picking up online nuances such as allowing extra time for technical issues, how to rearrange a space for participant safety, optimal preparation for sessions and how to verbally cue patients/clients online (Table 2).

\section{Theme 2: The online and project component of placements is valuable}

Students reported a link between their online and project-based elements and the "real world of work" (Table 2), particularly with the development of deliverables, while working collaboratively and/or pitching or presenting projects to stakeholders such as management teams. Students appreciated the projects required them to explore certain topics with depth (Table 2).

Table 2

Themes, subthemes and selected survey quotations from student survey.

Theme 1: The learning experience and skills required for clinical placements was varied

Communication is important in online and face-to-face settings, but the important aspects of communication vary

Teamwork and organisation are key in an online environment

Students want a 'hands on' component to clinical placements
'When having to deliver instructions over zoom, it became apparent that your word choice for cueing people needed to be modified.' (S3_SO_WHO)

'I also learnt more about time management and being self-motivated and selfsufficient with my work which I think has set me up well.' (21_SO_WO)

'Making sure for time managements sake that you email a participant ahead of time, with a list of equipment and a space that is ideal... also allow extra time for technical issues or to rearrange a space that may be a bit unsafe that the participant did not realise.' (3_SO_WO)

'I delivered a presentation and poster. Yes, I think it was useful to be able to dive deep into the current literature on the given topic. I think it was an appropriate assignment given the situation of COVID-19. But face-to-face placement would have been preferred if there was no COVID situation.' (24_SO_WO)

'I preferred my sports placement as it was more on-site and therefore, hands on. I felt like I learnt more as I was dealing with people in real life and was able to learn better skills.' (8_SH_WO)

Theme 2: The online and project component of placements is valuable

Projects allow students to explore topics in depth
'This project was extremely useful in understanding the biomechanics of different manual workers and creating a program to prevent common injuries at that workplace.' (18_SO_WO)

'I do think for both sports and WHS, that the projects we did would be amazing if we also got to be onsite. I think once COVID-19 has run its course it would be nice to combine the two, projects created alongside in-person placements.' (3_SO_WO).

'We created lots of deliverables, we took on a big project between the 2 of us that equates to $120 \mathrm{hrs}$. But we thoroughly enjoyed it... We did a presentation to the management team of the company, and even got to go onsite. It was a valuable experience that taught us lots about WHS Physiotherapy practice.' (21_SO_WO) 
Students recognise the link between skills gained in online and project-based placement and the 'real world'
'In my sports placement I learnt a skill that even though it was taught online, I could transfer it to in person when I start working, so I feel like I got a lot out of it.' (3_SO_WO)

'If you are working in a workplace you will need to observe and create things like this. Especially if you are working in a big company.' (4_SO_WO)

'I created an injury screening tool for equestrian riders geared toward remote delivery. I do think this was a useful skill and project. This is something that even without COVID is useable for this sport since you deal with athletes living, training, and competing all over the world at any given time. It also allows you to learn how to create an injury screening tool in general which I think is a useful skill regardless of what sport you work moving forward.' (3_SO_WO)

'The perfect mixture of online/ project-based components with on-site interactions was similar to how the workplace would run. I found this style of placement to be challenging and helpful.' (10_SO_WH)

'Creating resources based on a brief and pitching our product to the company was a valuable learning experience.' (11_SO_WO)

'I believe the deliverable was a useful part of the project-based placement not just in creating an outcome but experience working with different personalities and people.' (20_SO_WO)

Each quote is noted in brackets as to participant number, placement setting ( $\mathrm{S}=$ sport placement) and placement delivery $(\mathrm{O}=$ online or $\mathrm{H}=$ hybrid $)$ placement setting $(\mathrm{W}=$ work health and safety) and placement delivery $(\mathrm{O}=$ online or $\mathrm{H}=$ hybrid)

\section{Student performance}

In 2018/19, 118 students completed placements. In 2020, 58 students completed placements during the COVID-19 pandemic.

For sport placements, no student $(2018$ - 2020) received a score of 0 or 1 on the APP, indicating that all students had met the minimum standards. There was a significant difference in student performance between the 2018/2019 placements and 2020 placements on item 7 and 8 of the APP (Table 3). Post-hoc analysis demonstrated students in 2020 achieved significantly less scores of 4 on item 7 (performs a client-centred interview) in comparison to students in the 2018/2019 cohorts $(22 \%, 95 \%$ CI $3-36 \%)$ with no difference in the proportion of scores 2 and $3(p=0.10-0.22)$. Conversely, students in 2020 achieved significantly more scores of 4 on item 8 (selects and measures relevant health indicators and outcome) in comparison to students in the 2018/2019 cohorts $(23 \%, 95 \%$ CI $7-39 \%)$ and less scores of $3(19 \%, 95 \%$ CI $3-34 \%)$ with no difference in the proportion of 2 scores $(p=0.13)$.

A significant difference in student performance was also found between 2018/2019 and 2020 WHS placements for ICAT items 2 and 3 (Table 4). Post-hoc analysis demonstrated students in 2020 achieved significantly less 'advanced' scores on item 2 (client safety and quality) in comparison to students in the $2018 / 2019$ cohorts $(19 \%, 95 \%$ CI $3-33 \%)$ with no difference in the proportion of 'proficient' or 'functional' scores $(p=0.059-0.098)$. Students in 2020 also achieved significantly less 'advanced' scores on item 3 (collaborative practice) in comparison to students in the 2018/2019 cohorts (24\%, $95 \%$ CI $9-38 \%)$ and more scores of 'proficient' (23\%, $95 \%$ CI $8-38 \%$ ) with no difference in the proportion of 'functional' scores $(p=0.68)$.

When considering the number of missing or not applicable APP and ICAT items scored by educators, 12 of the 20 APP items $(60 \%)$ were assessed significantly less frequently in 2020 placements in comparison to the 2018/19 placements (Table 3). One item (APP item 6) was assessed more frequently in the 2020 cohort. All items were scored for all ICAT assessments. 
Table 3 The number of APP item scored between placements, the proportion of each score (\%), and the percentage difference between items scored ( $95 \%$ CI). *indicates p<0.05.

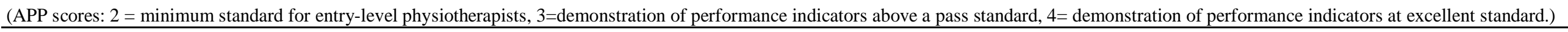
APP item

1: Demonstrates an understanding of clients rights and consent

2: Demonstrates commitment to learning

3: Demonstrates ethical, legal and cultural responsive practice

4: Demonstrates collaborative practice

5: Communications effectively and appropriately- verbal/ non-verbal

6: Demonstrates clear and accurate documentation

7: Conducts an appropriate client-centred interview

8: Selects and measures relevant health indicators and outcomes

9: Performs appropriate physical assessment procedures

10: Appropriately interprets assessment findings

11: Identifies and prioritises client's problems

12: Sets realistic short and long term client-centred goals

13: Selects appropriate intervention in collaboration with the client

14: Performs interventions appropriately

15: Is an effective educator

16: Monitors the effect of intervention

17: Progresses intervention appropriately

18: Undertakes discharge planning

19: Applies evidence based practice in client-centred care

20: Identifies adverse events/near misses and minimises risk associated with 3

assessment and interventions

\begin{tabular}{|c|c|c|c|c|c|}
\hline \multicolumn{6}{|c|}{ APP Score (\%) } \\
\hline 2 & & 3 & & 4 & \\
\hline $\begin{array}{l}2018 / \\
2019\end{array}$ & 2020 & $\begin{array}{l}2018 / \\
2019\end{array}$ & 2020 & $\begin{array}{l}\text { 2018/ } \\
2019\end{array}$ & 2020 \\
\hline
\end{tabular}

$P$ value Number of items Difference in the $\%$ of

scored missing item scores

(\%) 2018/2019 placement

2018/ 2020 minus

$2019 \quad 2020$ placement

$n=118 \quad n=58 \quad(95 \%$ CI $)$

$100 \quad 90 \quad-10(-21$ to -4$)$

$2 \quad 2 \quad 16$

$3 \quad 5 \quad 16$

22

$8 \quad 7 \quad 30$

$3 \quad 4 \quad 38$

$8 \quad 15$

14

$25 \quad 22$

$16 \quad 18$

$22 \quad 72$

18

19

$30 \quad 34$

$38 \quad 28$

$49 \quad 65$

$64 \quad 45$

64

56

55

42

52

53

51

42

38

50

47

54

27

0

31

$72 \quad 76$

.905

.766

100

$100 \quad 0(-6$ to 3$)$

$00 \quad 97 \quad-3(-12$ to 1$)$

$\begin{array}{llllll}74 & 79 & .705 & 100 & 100 & 0(-6 \text { to } 3)\end{array}$

59

.809

100

59

68

.477

92

21

$.045^{*}$

100

98

13 (4 to 21 )

\begin{tabular}{l}
$45-30 \quad 53$ \\
\hline
\end{tabular}

$.004^{*}$

100

59

$-41(-54$ to -29$)$

$-9(-19$ to -3$)$

$-41(-54$ to -29$)$

$-9(-19$ to -3$)$

$-3(-12$ to 1$)$

$-28(-40$ to -17$)$

$-12(-23$ to -5$)$

$-35(-47$ to -23$)$

$-14(-25$ to -6$)$

$-20(-32$ to -11$)$

$-18(-31$ to -8$)$

$-76(-85$ to -63$)$

$100 \quad 0$ (-6 to 3$)$

57

38

66

62

.370

100

$67 \quad-33(-46$ to -22$)$ 
Table 4

The number of ICAT item scored between placements, and the proportion of items scored in each category (\%) with p values. * indicates $\mathbf{p}<0.05$

\begin{tabular}{|c|c|c|c|c|c|c|c|c|c|}
\hline \multirow[t]{4}{*}{ ICAT item } & \multicolumn{6}{|c|}{ ICAT Score (\%) } & \multirow{2}{*}{\multicolumn{3}{|c|}{$\begin{array}{l}P \text { value Number of } \\
\text { items scored } \\
n(\%)\end{array}$}} \\
\hline & \multicolumn{2}{|c|}{ Functional } & \multicolumn{2}{|c|}{ Proficient } & \multicolumn{2}{|c|}{ Advanced } & & & \\
\hline & $\begin{array}{l}2018 / \\
2019\end{array}$ & 2020 & $\begin{array}{l}2018 / \\
2019\end{array}$ & 2020 & $\begin{array}{l}2018 / \\
2019\end{array}$ & 2020 & & $\begin{array}{l}2018 / \\
2019\end{array}$ & 2020 \\
\hline & & & & & & & & $n=118$ & $n=58$ \\
\hline 1: client-centred service & 3 & 3 & 40 & 48 & 57 & 48 & .556 & 100 & 58 \\
\hline 2: client safety and quality & 1 & 5 & 37 & 52 & 62 & 43 & $.023^{*}$ & 100 & 58 \\
\hline 3: collaborative practice & 2 & 3 & 29 & 52 & 69 & 45 & $.007 *$ & 100 & 58 \\
\hline
\end{tabular}

\section{Educator perspectives of novel online and project- based placements}

All eligible educators $(n=8)$ participated in the interview, and data saturation was achieved by the last interview with no new themes emerging. Demographic data of the educators are presented in Table 5.

Table 5

Demographics of educators

\begin{tabular}{|c|c|c|c|c|c|c|}
\hline \multirow[t]{2}{*}{ Educator } & \multirow[t]{2}{*}{ Setting } & \multirow[t]{2}{*}{ Role } & \multicolumn{2}{|c|}{$\begin{array}{l}\text { Number of } \\
\text { students taken }\end{array}$} & \multicolumn{2}{|c|}{$\begin{array}{l}\text { Format, type of placement } \\
\text { undertaken }\end{array}$} \\
\hline & & & 2019 & 2020 & 2019 & 2020 \\
\hline$\overline{\mathrm{E} 1}$ & WHS & $\begin{array}{l}\text { Human Resources } \\
\text { Manager }\end{array}$ & 4 & 15 & F2F, project & Online, project \\
\hline $\mathrm{E} 2$ & WHS & WHS Advisor & 2 & 3 & $\mathrm{~F} 2 \mathrm{~F}$, project & Online, project \\
\hline E3 & WHS & WHS Advisor & 2 & 2 & $\mathrm{~F} 2 \mathrm{~F}$, project & Online, project \\
\hline $\mathrm{E} 4$ & WHS & WHS Manager & 8 & 8 & $\mathrm{~F} 2 \mathrm{~F}$, project & Online, project \\
\hline E5 & WHS & $\begin{array}{l}\text { Human Resources } \\
\text { Manager }\end{array}$ & 6 & 6 & $\mathrm{~F} 2 \mathrm{~F}$, onsite & Online, project \\
\hline E6 & Sport & Physiotherapist & 2 & 8 & F2F, on field & Online, project \\
\hline E7 & Sport & Physiotherapist & 4 & 8 & $\mathrm{~F} 2 \mathrm{~F}$, on field & $\begin{array}{l}\text { Hybrid (online, } \\
\text { project, F2F, on } \\
\text { field) }\end{array}$ \\
\hline E8 & Sport & Physiotherapist & 4 & 4 & $\mathrm{~F} 2 \mathrm{~F}$, on field & Online, project \\
\hline
\end{tabular}

$\mathrm{F} 2 \mathrm{~F}=$ face-to-face 
Two main themes were derived from the interviews. Subthemes and illustrative quotations are provided in Table 6.

\section{Theme 1: Online or project-based component mirror real world practice}

The inclusion of online and project-based work was considered by educators in both placement settings to be a better reflection of their work than the fully face-to-face placements used prior to 2020 (Table 6). Many educators reported project-based placements increased the depth of the learning experience for students in their project topic. Many educators also considered the inclusion of online communication, research and presentation of work, to increase the breadth of the learning experience for students in online placements (Table 6).

\section{Theme 2: Changes made to placements due to COVID-19 altered the experience of all stakeholders (students, educators, and businesses)}

The experience of educators during online placements in 2020 differed to that of previous onsite placements, and educators reported that they believed students also had a different experience. Communication and organisation were key student skills that were more noticeable with online delivery (Table 6). The majority of educators reported student projects completed within project-based placements exceeded their expectations in regard to presentation and content, and these deliverables would be useful to businesses (Table 6).

Table 6

Themes, subthemes and selected educator quotations

Each quote is noted in bracket as to the Educator (E) number and setting. $\mathrm{S}=$ sport, W=WHS

Theme 1: Placements that included an online or project-based component mirror real world practice

Input (research and data analysis) and output (presentations and justification of decisions)

\begin{abstract}
'I think we'll do a mix, definitely, especially because they are so independent as well. Once they've done that kind of on-site component, and they are more into the development of the materials, or the project or whatever else ... there is no reason why they have to be in an office, I mean, I'm not even in the office every day now, so definitely, they can do it from home, or remotely.' (E2_W)

'They get to see the communication that we have, communication between me with, for example, the coach the manager the player and how that works and how it's really important you can't leave one person out of it...they get to see the detailed injury reports that we send off and they get to see the what happens throughout a week that no one sees on a weekend. So they (the students) know that the work doesn't end when you leave at $5 \mathrm{pm}$. It's ongoing patient care, just being able to be witness to that is important.' (E7_S)
\end{abstract}

'We tried to make it as real as possible, and they had to present online to senior stakeholders... so that was a very real business scenario that hopefully they took from it.' (E4_W)

Utilising technology
'The advantage for the 2020 group was to really learn to work in a virtual world, and that might become significantly more commonly, based on COVID- 19 ... they need to be able to mentally transition to virtual and work in a virtual world is important... and that is significant.' (E1_W)

Theme 2: Changes made to placements due to COVID-19 varied the experience of all stakeholders things that, you can look at a textbook and doesn't get you there, you can do what with a student in a viva but again you're not going to get the same as what you get when you actually see it at the pace that happens in the real world.' (E7_S)

(Face-to-face placement) 'They get to develop a relationship with a coach or a strength and conditioning coach and they so they kind of didn't get any of that with just doing the project aspect of it.' (E7_S) 


\begin{tabular}{|c|c|}
\hline & $\begin{array}{l}\text { 'To the credit of the students, some of them decided, like, where we've got glaziers carrying } \\
\text { large pieces of glass, they got big pieces of wood, like wooden cut outs and they tried to } \\
\text { carry them just so they could understand how a glazier would carry a large piece of glass, so } \\
\text { they would like, took their own initiative to really try and understand the task.' (E2_W) } \\
\text { 'I think (in online, project-based placements) they (the students) needed to have } \\
\text { more initiative, definitely, and a lot more self-motivation, I would probably say... I think } \\
\text { you have to be a little more self-motivated to do the online, complete remote } \\
\text { program.' (E2_W) } \\
\text { (speaking of online placements) 'Obviously not getting to meet the students, not getting out } \\
\text { those informal corridor conversations with them, little things like coming and visiting, and } \\
\text { going to the staff canteen, actually experiencing [company name] would have been a } \\
\text { disadvantage for them.' (E4_W) }\end{array}$ \\
\hline Educators & $\begin{array}{l}\text { 'With face-to-face you build richer communication, and probably have more informal } \\
\text { support throughout the placement.' (E2_W) } \\
\text { '(In the) Virtual world holding ourselves accountable to do the work we say in the virtual } \\
\text { world, so building that skill would be in myself and in the students, in my mind is really } \\
\text { important.' (E1_W) } \\
\text { 'Yeah I think virtual, you need more time upfront to plan and prepare for it, but when you } \\
\text { are doing it, it takes less of your time... whereas face-to-face, you probably need to prepare } \\
\text { less, but you need a lot more time during the program.' (E2_W) } \\
\text { 'Biggest challenge for me was coming up with projects that, don't need a lot of } \\
\text { hands on. But I mean that that could work, it just makes me think more creatively.' (E3_W) } \\
\text { 'The virtual time block was so was tight. They had an hour, so if they didn't think of } \\
\text { something in that hour that they wanted to talk about or didn't think of it prior to the } \\
\text { hour and bring it to the hour to talk about they really missed out on that chance to have } \\
\text { continuous collaboration.' (E1_W) } \\
\text { 'It probably it was less time intensive for myself and [educator name]. You know just } \\
\text { having visitors on site, arranging rooms catering, having face-to-face conversations- that's } \\
\text { all great stuff, but if we're looking at it from a time perspective, it's a lot more efficient to } \\
\text { log onto a meeting, and you know you've got } 30 \text { to } 40 \text { minutes, and you just get through it } \\
\text { and then you can move on to the next meeting.' (E4_W) } \\
\text { 'I hadn't happened as much as I thought it had.' (E1_W) }\end{array}$ \\
\hline Businesses & $\begin{array}{l}\text { 'I think that (businesses) all going down that path of that more hybrid way of working, I } \\
\text { mean obviously last year showed us that companies have the technology for people to be } \\
\text { able to work from home and the can be there and it does really squash that idea of that } \\
\text { presenteeism.' (E5_W) } \\
\text { 'Obviously for the business or a practice like us we will retain the resources that the } \\
\text { students helped us create and that might be a resource we can use in the future with a team, } \\
\text { or even the same teams next year. We got something tangible out of it that we can use } \\
\text { moving forward.' (E8_S) } \\
\text { 'In summary, for me it we have quite an extensive injury database we collect and we have } \\
\text { like this online it's called the athlete tracking system, so we do collect a lot of data so from } \\
\text { that perspective, we had a lot of data that could be analysed which I personally lack time } \\
\text { analysing, so for us in that setting it was really beneficial for someone to be able to analyse } \\
\text { the data, understand which injuries are common in AFL and again, you can research that } \\
\text { too, but to then see first-hand for the club you're about to work with, where do our injuries } \\
\text { lie.' (E7_S) } \\
\text { 'I think workplaces are generally now are moving into that whole output project base- what } \\
\text { are you delivering... I don't care about the hours you are working, as long as what you need } \\
\text { to do is being done.' (E5_W) }\end{array}$ \\
\hline
\end{tabular}




\section{Evaluation of COVID-19 placements}

Integration of the findings from all components of this study are presented in Figure 1, demonstrating the learning experience, skill requirements, and the real-world representation differed for online and projectbased placements. Subsequently, learning from the experiences of COVID-19 placement changes, a hybrid approach to sport and WHS placements is recommended.

\section{Figure 1}

Conceptual links between integrated themes, and learnings from COVID-19 affected placements.

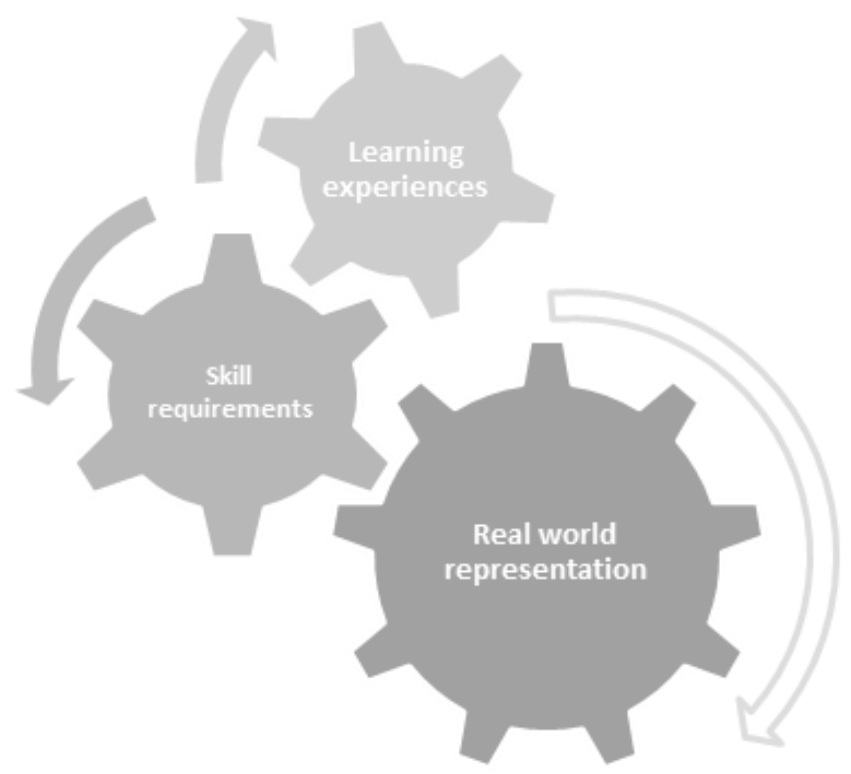

\section{Integrated Theme 1: Learning experiences in online placements differed compared to face to face placements}

Students recognised online placements allowed them to develop useful skills for their future studies or careers (Table 1). Analysis of itemised APP data showed items relating to patient assessment and history, performing physiotherapy intervention, discharge planning and risk management were assessed significantly less times in 2020 than in previous years (Table 3). This demonstrates that different skills are assessed for face-to-face and online or hybrid placements. Educators acknowledged some students missed exposure to discipline specific skills that only onsite placements can offer:

It is a shame to lose the experience of doing an assessment, having to interact with junior athletes and you've often got parents there as well...deciding whether or not they (the athletes) can or can't play on, making those sorts of decisions. (E6_S).

\section{Integrated Theme 2: Varied skill set requirements}

As presented in Table 2 , students recognised new and different skill sets were required for online and project-based elements, including communication, organisation, time management and telehealth consultation skills. Analysis of assessment data demonstrated a lower percentage of students received the highest score when conducting client-centred interviews (APP item 7) within 2018/2019 sport placements, whereas a higher percentage of students achieved the highest score in selecting and measuring relevant health indicators and outcomes (APP item 8) (Table 3). Analysis of WHS student performance revealed that a lower percentage of students received "advanced" scores in item 2 (client safety and quality) and 3 (collaborative practice) during 2020 WHS placements (Table 4). This was also supported by educators:

If they had been on site it was easier just to have a quick catch up and see where they're at with the project and it's harder also to really assess who's doing their share of the workload. (E5_W) 
Educators referenced a change in their role and the skills they required as educators of online placements, including planning, organisation, communication and facilitating students for self-directed learning (Table 6). However, the majority of students reported educators provided adequate contact and support when undertaking placements in a fully online environment (Table 1).

Educators also acknowledged the altered requirements for student skills depended upon the delivery of placements: skills that were more common in onsite/ on field settings were decision making, critical thinking under time pressure and physiotherapy assessment, whereas skills considered more prevalent in online placements were initiative, research skills, and self-directed learning. Educators agreed communication skills were required in both settings, but different aspects of this skill were necessitated in each (Table 6).

\section{Integrated Theme 3: Both formats represent real world work}

Most students recognised that the skills they developed while creating deliverables from their projects would help them in their future careers or studies (Table 2). Similarly, educators acknowledged student skills developed in the online world and associated with project-based work, such as research and presentation, were transferable to employment in both WHS and sport settings:

Looking at business at the moment, where so many are moving towards a bit more of a hybrid model, so where face-to-face teams come in to do meetings, but it's also a lot more online and it's very much the part that's staying. (E4_W)

\section{Learnings from COVID-19}

The majority of students recognised the skills developed in online and hybrid placements would be useful for their future careers (Table 1) and established a link between these placement elements to the real world of work. Although more students recommended that placements in the sport setting be entirely face-to-face compared to WHS placements, a hybrid approach is viewed as valuable to students (Table 2). Similarly, educators recommended the continuation of the hybrid approach for future placements (Table 6).

\section{Discussion}

This mixed methods study revealed that students and educators believed placements in sport and WHS settings involving online and project-based practice altered the learning experience of students when compared with traditional face-to-face placements conducted entirely onsite. This change was recognised as valuable, although could not replace some of the richness gained through onsite, face-to-face interactions, particularly in the sport setting. Online and project-based placements required different skills to be utilised by both students and educators, and this was supported by the differences found in assessment of student performance in 2020 COVID-19 affected placements. Projects allowed students to engage deeply in real-world problems and produce tangible deliverables that are seen to be useful to businesses and sporting clubs. These different skills and learning experiences were considered representative of the real world of work, and therefore highly useful. A hybrid approach was recommended for future placements, incorporating both onsite and online elements, as well as projectbased work which considered the discrete clinical skills required for different settings.

The evaluation of placements in this study highlighted how important it is for placements to keep up with changes to the way contemporary physiotherapists work. Placement experiences, by the nature of their diversity, offer varied learning experiences to students, however, there were patterns of difference found between the experiences of students who undertook face-to-face placements as opposed to those who completed online placements. Our study found the skills required to be successful in an online environment differed from those of face-to-face. The flexibility afforded by the ability to work online remotely required discipline and self-motivation, initiative, and professional skills to communicate and build relationships with both clients and colleagues online. All of the new skills identified in our study are not only supported by previous research of student placements (Overton, 2009; Prigg \& Mackenzie, 2002), they are also reflected in the experiences of health professionals delivering telehealth services during the COVID-19 pandemic (Cottrell \& Russell, 2020; Malliaras et al., 2021; Mitchell, 2021). The development of these new skills was noted to be of value to students, but when undertaken in the context of online and project-based placements students may need additional support. This was offered at an adequate level by the majority of educators even in a fully online environment. However, further 
development of these skills require consideration within academic curricula, as well as additional support for educators as required. A similar recommendation has been made to support health professionals delivering telehealth services (Cottrell \& Russell, 2020). Surveys of health professionals demonstrate up to two thirds reported not using telehealth prior to the pandemic (Malliaras et al., 2021), and more than $80 \%$ of physiotherapists did not have training prior to offering telehealth service (Australian Physiotherapy Research Foundation, 2020), which may have contributed to the difficulties faced by health professionals in pivoting quickly into the telehealth space (Malliaras et al., 2021). For 2021, Macquarie University DPT has incorporated telehealth training into the foundational units for first year students to support the development of these future focused skills. Telehealth has taken a major role in the delivery of all facets of healthcare during COVID-19 (Hassan et al., 2020; Monaghesh \& Hajizadeh, 2020; Taylor et al., 2021) and is likely to remain in some form as routine care in a post pandemic world (Taylor et al., 2021). Therefore, it is important for all future health professional students to develop the specific skills required to ensure the ongoing success of telehealth. While this study only involved physiotherapy placements within one institution, we surmise that the findings of this study will also have applicability to other health professions education programs.

Assessment of student performance on placement should highlight the important knowledge, skills and attributes required for professional practice. The results of this study showed the proportion of items assessed varied between 2018/2019 and 2020 COVID-19 affected sport placements, suggesting that some APP items are not applicable for sport placements delivered in an online or hybrid format. Similar to recent results comparing APP assessments between public and private sector placements (Lawton et al., 2021), these results suggest a more holistic assessment that could be used across the depth and breadth of settings in which contemporary physiotherapists work may require consideration.

While project-based and online elements were seen as a valuable learning experience, and the skills required to be successful in an online environment noted, educators recognised the skill set developed through face-to-face contact cannot be replaced. Similar to previous research in project-based and online placements, students and educators felt there was a missed opportunity to develop key clinical skills (Friedland et al., 2001; Twogood, R. 2020). This study showed that the combination of online and faceto-face formats, project-based and onsite types of placement into a hybrid approach was recommended by both students and educators. A hybrid placement would allow for the richness offered from time onsite, including the development of rapport with team members, exploration of the physical context, and the development of discipline specific skills that are undertaken in a face-to-face environment, whilst also supporting the development of a different set of skills essential to the online context. The benefits of time to work in depth on a real-world project, as well as flexibility of working remotely offer a truly hybrid approach that supports the development of real-world skills. Including online and project-based components to a placement would enhance, but not replace face-to-face placements (Walker et al., 2020).

In this study, educator participants, although small in number, were somewhat diverse in regard to setting, placement type and experience. We achieved data saturation in the themes derived from interviews, and through team checking and discussion, are confident the findings reflect the full range and depth of the reflection and evaluation. Similarly, student responses were varied and reflect a diversity of student experiences of placement context and types of work undertaken. However, we acknowledge some potential limitations. In our analysis of student performance, the assessment tools we have used (the ICAT and APP) have not been validated for these settings. Nevertheless, educators receive training and support by the clinical education team at Macquarie University, and these tools have been used consistently within these placements over eight years. We also recognise the six month delay in survey administration from the completion of these placements may have contributed to the small sample size within the student survey $(41 \%)$. The mixed delivery mode of placements, including online and face-toface, and a mix of work undertaken, including project-based and onsite elements, makes it challenging to extract clarity around exactly what form of hybrid approach may work best in which setting. This may be worth examining in more depth as students undertake hybrid style placements in the future.

\section{Conclusion}

As COVID-19 has altered the landscape for future-focused healthcare professionals it should also change the way in which clinical placements in healthcare settings are executed. Students entering into a postCOVID healthcare workforce require a different but important set of skills in addition to those gained by entirely face-to-face placements. The results of this study show the inclusion of project-based and online 
elements into placements provide genuine and valuable learning opportunities and should therefore, be incorporated in future placements.

\section{Acknowledgements}

The authors would like to thank both the students and educators, whose flexibility and adaptability with their learning and educating helped to shape the findings of this project. In addition, we would like to thank Tina Vickery for her help in interviewing.

\section{Sources of funding}

No funding was received for this project.

\section{ORCID}

Vidya Lawton

https://orcid.org/0000-0003-1734-1330

Rebecca Vaughan

https://orcid.org/0000-0003-2295-5759

Taryn .M. Jones

https://orcid.org/0000-0003-3809-2126

Verity Pacey

https://orcid.org/0000-0002-5577-2732

\section{References}

Australian Physiotherapy Research Foundation. (2020). Telehealth by physiotherapists in Australia during the COVID-19 pandemic. Interim Report: October 2020. https://australian.physio/sites/default/files/RESEARCH\%26PUBLICATIONS/PRF/APA_PRF_ Telehealth-interim-report.pdf

Bacopanos, E., \& Edgar, S. (2015). Employment patterns of Notre Dame graduate physiotherapists 200612: targeting areas of workforce need. Australian Health Review, 40(2), 188-193. https://doi.org/10.1071/AH14244

Brewer, M. (2015). Curtin University's Interprofessional Capability Assessment Tool Final Year Students. - https://healthsciences.curtin.edu.au/wpcontent/uploads/sites/6/2015/10/Interprofessional_Capability_Assessment_Tool_Final_Year_Stu dents1.pdf

Brewer, M. L., \& Stewart-Wynne, E. G. (2013). An Australian hospital-based student training ward delivering safe, client-centred care while developing students' interprofessional practice capabilities. Journal of Interprofessional Care, 27(6), 482-488. https://doi.org/10.3109/13561820.2013.811639

Corbin, J. M., \& Strauss, A. L. (2008). Basics of qualitative research: techniques and procedures for developing grounded theory (3rd ed.). Sage.

Cottrell, M. A., \& Russell, T. G. (2020). Telehealth for musculoskeletal physiotherapy. Musculoskeletal Science \& Practice, 48, 102193-102193. https://doi.org/10.1016/j.msksp.2020.102193

Dalton, M., Davidson, M., \& Keating, J. (2011). The Assessment of Physiotherapy Practice (APP) is a valid measure of professional competence of physiotherapy students: a cross-sectional study with Rasch analysis. Journal of Physiotherapy, 57(4), 239-246. https://doi.org/10.1016/S18369553(11)70054-6

Dalton, M., Davidson, M., \& Keating, J. L. (2012). The Assessment of Physiotherapy Practice (APP) is a reliable measure of professional competence of physiotherapy students: A reliability study. Journal of Physiotherapy, 58(1), 49-56. https://doi.org/10.1016/S1836-9553(12)70072-3

Dalton, M, Keating. J., Davidson, M. (2009). Development of the Assessment of Physiotherapy Practice (APP): A standardised and valid approach to assessment of clinical competence in physiotherapy, Final report, March 2009. Australian Learning and Teaching Council (ALTC). www.altc.edu.au

Darling-Hammond, L, Barron, B., Pearson, D.P., Schoenfeld, A.H., Stage, E.K., Zimmerman ,T. D., Ceretti, G. N, \& Tilson, J. (2008). Powerful learning: What we know about teaching for understanding. Jossey-Bass. 
DeClute, J., \& Ladyshewsky, R. (1993). Enhancing clinical competence using a collaborative clinical education model. (includes commentary and author response). PTJ: Physical Therapy \& Rehabilitation Journal, 73(10), 683-689. https://doi.org/10.1093/ptj/73.10.683

El-Awaisi, A., Anderson, E., Barr, H., Wilby, K. J., Wilbur, K., \& Bainbridge, L. (2016). Important steps for introducing interprofessional education into health professional education. Journal of Taibah University Medical Sciences, 11(6), 546-551. https://doi.org/10.1016/j.jtumed.2016.09.004

Friedland, J., Polatajko, H., \& Gage, M. (2001). Expanding the Boundaries of Occupational Therapy Practice through Student Fieldwork Experiences: Description of a Provincially-Funded Community Development Project. Canadian Journal of Occupational Therapy, 68(5), 301-309. https://doi.org/10.1177/000841740106800506

Guo, P., Saab, N., Post, L. S., \& Admiraal, W. (2020). A review of project-based learning in higher education: Student outcomes and measures. International Journal of Educational Research, 102, 101586. https://doi.org/10.1016/j.ijer.2020.101586

Hassan, A., Mari, Z., Gatto, E. M., Cardozo, A., Youn, J., Okubadejo, N., Bajwa, J. A., Shalash, A., Fujioka, S., Aldaajani, Z., Cubo, E., Adams, J., Afshari, M., Aldred, J., Ben-Pazi, H., Bloem, B., Browne, P., Buesing, K., Chan, B., Chouinard, S., Doumbe, J., Dekker, M., Galifianakis, N., Gatto, E., Goetz, C., Guttman, M., Hatcher-Martin, J., Katz, M., Moukheiber, E., Ojo, O., Pantelyat, A., Prakash, N., Spindler, M., \& Tanner, C. (2020). Global survey on telemedicine utilization for movement disorders during the COVID-19 pandemic. Movement Disorders, 35(10), 1701-1711. https://doi.org/10.1002/mds.28284

Herbert, R. (2013). Confidence Interval Calculator. https://pedro.org.au/english/resources/confidenceinterval-calculator/

Hunt, S. G. (2005). Participatory Community Practice: A Community-based Rehabilitation Curriculum in Occupational Therapy and Lessons Learned through Partnerships with Undergraduate Students. World Federation of Occupational Therapy Bulletin, 51(1), 14-18. https://doi.org/10.1179/otb.2005.51.1.003

Lawton, V., Jones, T. M., \& Dean, C. M. (2021). Students achieve comparable performance scores for clinical placements in public and private sectors: a longitudinal observational study. Journal of Physiotherapy, 67(1), 56-61. https://doi.org/10.1016/j.jphys.2020.12.001

Lee, J. S., Blackwell, S., Drake, J., \& Moran, K. A. (2014). Taking a leap of faith: Redefining teaching and learning in higher education through project-based learning. Interdisciplinary Journal of Problem-based Learning, 8(2). https://doi.org/10.7771/1541-5015.1426

Malliaras, P., Merolli, M., Williams, C. M., Caneiro, J. P., Haines, T., \& Barton, C. (2021). 'It's not hands-on therapy, so it's very limited': Telehealth use and views among allied health clinicians during the coronavirus pandemic. Musculoskeletal Science \& Practice, 52, 102340. https://doi.org/10.1016/j.msksp.2021.102340

Milanese, S., Gordon, S., \& Pellatt, A. (2013). Undergraduate physiotherapy student perceptions of teaching and learning activities associated with clinical education. Physical Therapy Reviews, 18(6), 439-444. https://doi.org/10.1179/1743288X12Y.0000000060

Mitchell, M. (2021). Getting to the heart of cardiac rehabilitation. Physiotherapy in Motion, Feb 01. https://australian.physio/inmotion/getting-heart-cardiac-rehab

Monaghesh, E., \& Hajizadeh, A. (2020). The role of telehealth during COVID-19 outbreak: a systematic review based on current evidence. BMC Public Health, 20(1), 1193. https://doi.org/10.1186/s12889-020-09301-4

Overton A, Clark, M., Thomas Y. (2009). A Review of Non-Traditional Occupational Therapy Practice Placement Education: A Focus on Role-Emerging and Project Placements. British Journal of Occupational Therapy. 72(7), 294-301. https://doi.org/10.1177/030802260907200704

Preston, E., Ada, L., Dean, C. M., Stanton, R., Waddington, G., \& Canning, C. (2012). The Physiotherapy eSkills Training Onlineresource improves performance of practical skills: a controlled trial. BMC Medical Education, 12, Article 119. https://doi.org/10.1186/1472-6920-12-119

Prigg, A., \& Mackenzie, L. (2002). Project placements for undergraduate occupational therapy students: design, implementation and evaluation. Occupational Therapy International, 9(3), 210-236. https://doi.org/10.1002/oti.166

Seymour-Walsh, A. E., Bell, A., Weber, A., \& Smith, T. (2020). Adapting to a new reality: COVID-19 coronavirus and online education in the health professions. Rural and Remote Health, 20(2). https://doi.org/10.22605/RRH6000

Taylor, A., Caffery, L. J., Gesesew, H. A., King, A., Bassal, A.-R., Ford, K., Kealey, J., Maeder, A., McGuirk, M., Parkes, D., \& Ward, P. R. (2021). How Australian Health Care Services Adapted to Telehealth During the COVID-19 Pandemic: A Survey of Telehealth Professionals. Frontiers in Public Health, 9, 121. https://doi.org/10.3389/fpubh.2021.648009 
Twogood, R., Hares, E., Wyatt, M., \& Cuff, A. (2020). Rapid implementation and improvement of a virtual student placement model in response to the COVID-19 pandemic. BMJ Open Quality, 9(4). http://doi.org/10.1136/bmjoq-2020-001107

Walker, R. C., Tong, A., Howard, K., Darby, N., \& Palmer, S. C. (2020). Patients' and caregivers' expectations and experiences of remote monitoring for peritoneal dialysis: A qualitative interview study. Peritoneal Dialysis International, 40(6), 540-547.

https://doi.org/10.1177/0896860820927528 


\section{Appendix 1. Interview Guide for Educators}

\section{Demographic Questions}

(1) How many years have you been taking Macquarie University students for, and how many did you take in 2020 ? In previous years?

(2) What is your role within your field?

(3) What did your placements look like in 2020? In previous years?

\section{Questions for semi- structure in depth interview}

(1) During 2020 placements, what changes did you have to make due to the impact of COVID-19 on the ability to deliver placements face to face? How did this change impact on you (placement organisation, placement delivery)?

(2) In changing the delivery of placements in 2020, do you think students gained different skills? If so, what skills and why?

(3) In comparing 2020 placements to previous years, do you think there are any advantages? Disadvantages?

(4) Do you think 2020 placements provided a valuable learning experience? Why or why not?

(5) Looking into the future of placements, are there elements of the placements you ran last year that you are looking to keep? Why or why not? 